\title{
New Ambulatory Hysteroscopic Septoplasty using Ballooning in a Woman with Complete Septate Uterus: A Case Report
}

\author{
†Jung Hyun Cho, Hyung Jae Won, Mi Kyoung Kim, Ju Hee Park, and Ju Youn Hwang \\ Sarang I IVF Center, Seoul 05556, Korea
}

\begin{abstract}
A 40-year-old G1 P0 L0 A1 woman was referred to our clinic with 6-year history of infertility. Before visiting the clinic, she had 3 cycles of In-Vitro Fertilization (IVF) procedures ( 2 cycles of Controlled Ovarian Stimulation-IVF and 1 cycle of frozen-thawed Embryo Transfer (ET)) at other clinic. She had medical history of abortion at early gestation following FET (frozen-thawed-ET). The patient had complete type of septate uterus, double cervix and longitudinal vaginal septum. Vaginal septotomy was done first and 1 month later, hysteroscopic septoplasty was followed using ballooning filled with dye. After septoplasty, we inserted ballooning and left for several days to compress septal endometrium on the septectomy area. All procedures were done in the ambulatory operating room without laparoscopy or admission. 3 months later, she had in vitro fertilization-embryo transfer (IVF-ET) and FET procedures in our clinic. She had successful pregnancy and now is at 22 weeks of gestation. New ambulatory septoplasty using dye-filled ballooning is easy, safe and minimally invasive surgery for treatment of complete septate uterus.
\end{abstract}

Key words : Infertility, In vitro fertilization-embryo transfer (IVF-ET), Septate uterus, Ballooning, G1 P0 L0 A1

\section{INTRODUCTION}

Septate uterus is the most common uterine malformation of the female reproductive tract. It is due to abnormal resorption of the Müllerain canal during embryogenesis (Chan et al., 2011). Uterine septum causes various obstetric complications such as infertility, miscarriage, abnormal fetal position and premature birth (Grimbizis et al., 2001). In patients with dyspareunia, spontaneous miscarriage and infertility, surgical intervention may be beneficial (Chen et al., 2013). The septate uterus is classified into two types: complete type and incomplete type (The American Fertility Society, 1988).

Hysteroscopic septoplasty is a safe, easy and recom- mendable surgery in treatment of incomplete type of septate uterus (Esmaeilzdeh et al., 2014). When hysteroscope is inserted into hemiuterus, it is difficult to evaluate the exact septal area (Fedele et al., 1995). MRI before surgery may be informative for measurement of length and width of septal wall, but not for the initial cutting point of septal wall.

Concomitant laparoscopy is helpful for prevention of uterine perforation but it also cannot visualize the initial point of cutting septal wall (Tajiri et al., 2015). Dye-filled ballooning in a hemiuterus can be easily seen at the opposite site of hemiuterus by hysteroscopy. Pulling the tail of balloon can make the septal wall bulge towards the opposite side. Then we can easily decide which part of septum to cut. Once we make a hole on the septum, we dissect

\footnotetext{
Manuscript received March 10, 2018, Received in revised form March 18, 2018, Accepted March 24, 2018

${ }^{\dagger}$ Corresponding Author : Jung Hyun Cho, Sarang I IVF Center, Seoul 05556, Korea. Tel: +82-10-3181-3210, Fax: +82-2-419-7588, E-mail: medicho@ hotmail.com

This is an Open Access article distributed under the terms of the Creative Commons Attribution Non-Commercial License (http:// creative-commons.org/licenses/by-nc/3.0) which permits unrestricted non-commercial use, distribution, and reproduction in any medium, provided the original work is properly cited.
} 
subendometrial area by optic scissors to separate septal endometrium and septal myometrium.

We only cut out septal myometrium by optic scissors leaving septal endometrium intact.

\section{CASE}

A 40-year-old G1 Po Lo A1 woman was referred to our clinic with 6-year history of infertility. She had 3 cycles of IVF procedures ( 2 cycles of Controlled Ovarian Stimulation-IVF and 1 cycle of frozen-thawed ET). She had medical history of abortion at early gestation following FET (frozen-thawed-ET). Pelvic exam revealed normal external genitalia, a longitudinal vaginal septum and two cervix (Fig. 1).

After septotomy of longitudinal vaginal septum, hysterosalpingogram (HSG) was done. It showed two independent hemiuterus and normal spillage of both tubes (Fig. 2).

Transvaginal ultrasonography showed Y shaped uterine cavity, two chambers of upper parts and two fixed lower parts of uterine cavity (Fig. 3).

Before hysteroscopy insertion, we inserted a foley catheter into one hemiuterus and infused indigo calmin $(2.0 \mathrm{cc})$ to make ballooning. Then, we inserted hysteroscope into the other one of hemiuterus so we can cut the bulging area

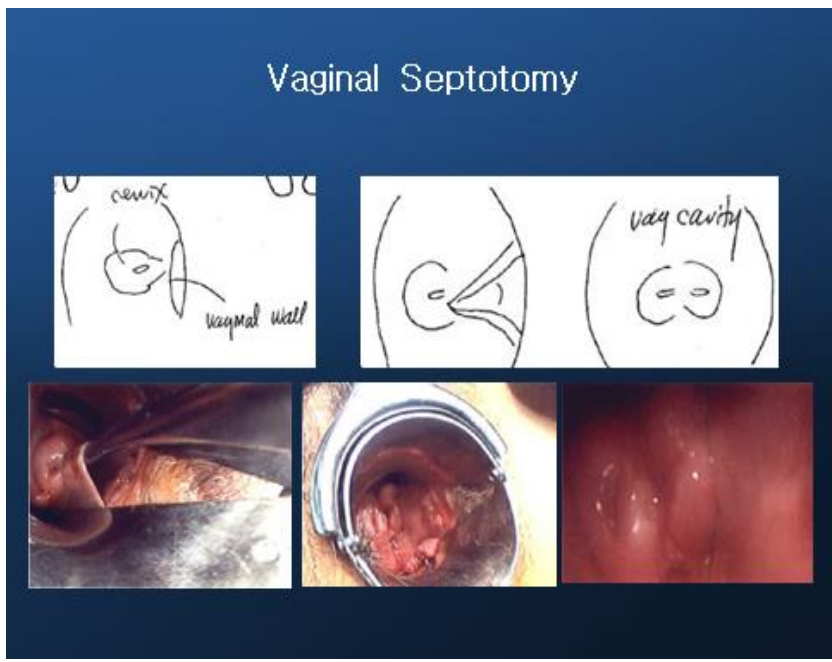

Fig. 1. Vaginal septum, post septotomy, two cervix. of septal wall. Bulging site of septum was noted and a hole made between two hemiuterus (Figs. 4 and 5).

We dissected subendometrial area of septum from the hole and removed septal myometrium and preserved septal endometrium (Fig. 6).

After resection of septal myometrium, we inserted foley balloon catheter and ballooning $(3.0 \mathrm{cc})$ to compress the septal endometrium around the septectomy area (Fig. 7).

After 1 month, postop HSG was done. HSG shows flat

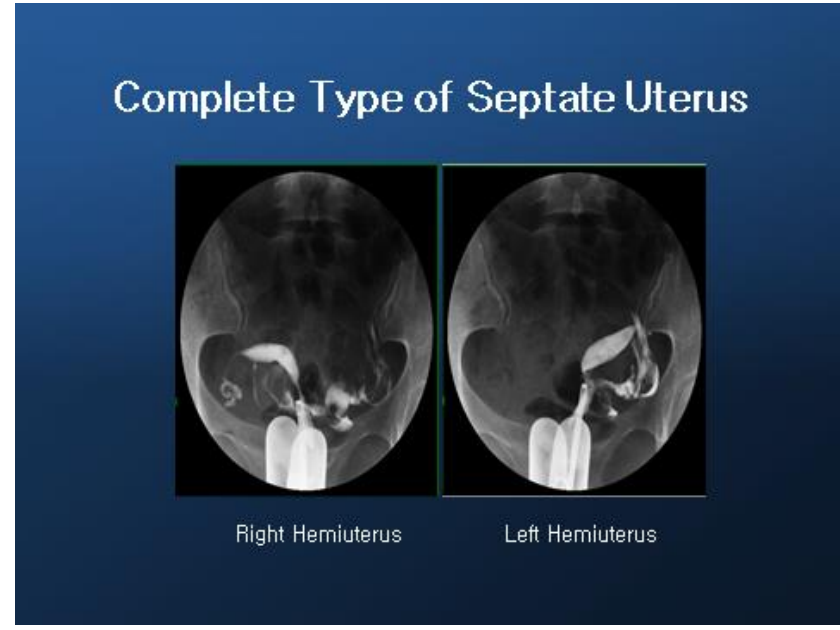

Fig. 2. HSG of complete type of septum : two independent hemiuterus. HSG, hysterosalpingogram.

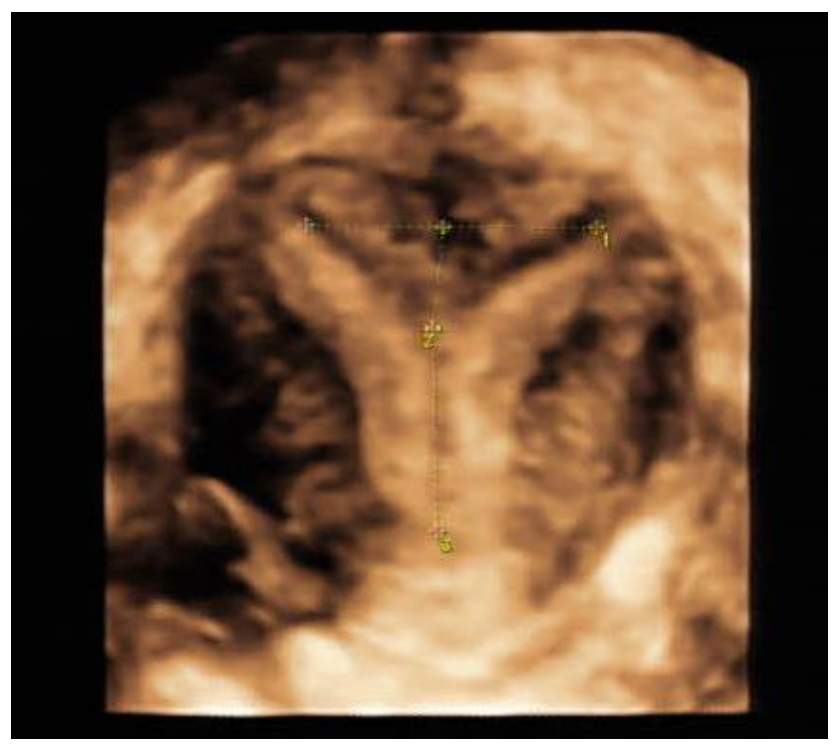

Fig. 3. Transvaginal ultrasonography of complete type of septate uterus. 

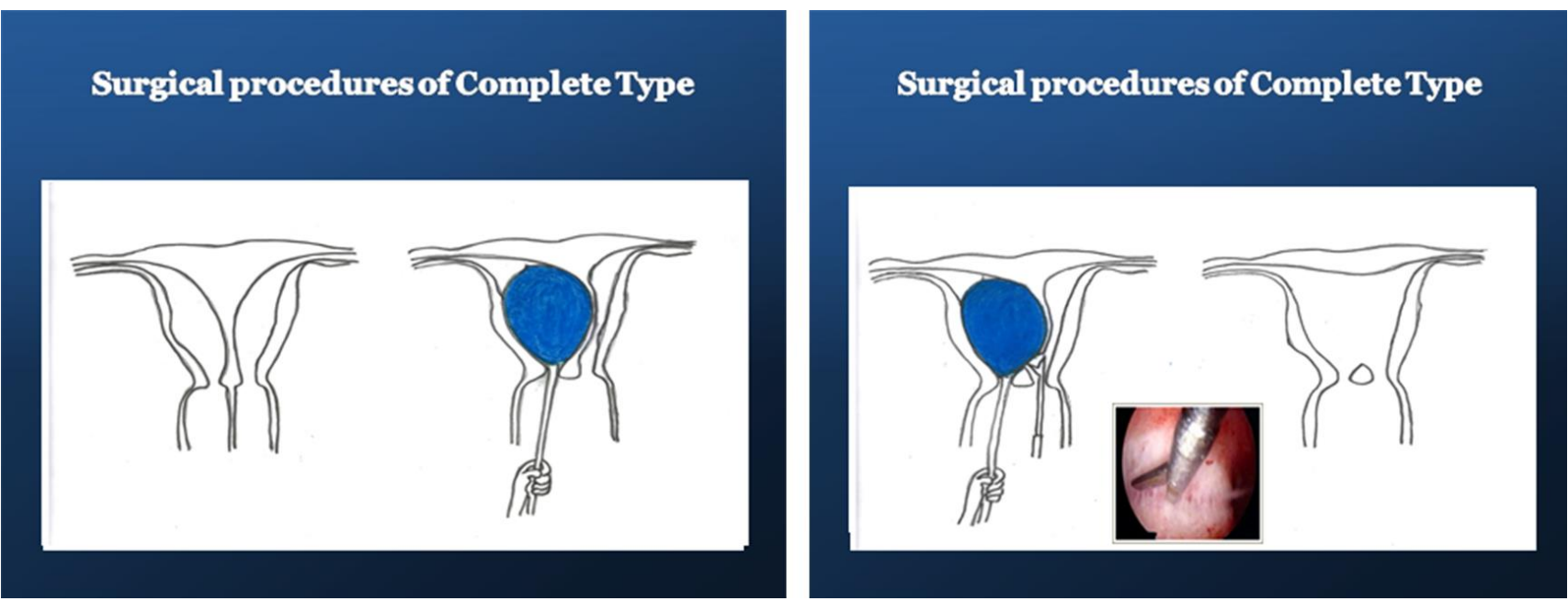

Fig. 4. Septectomy using dye-filled ballooning.
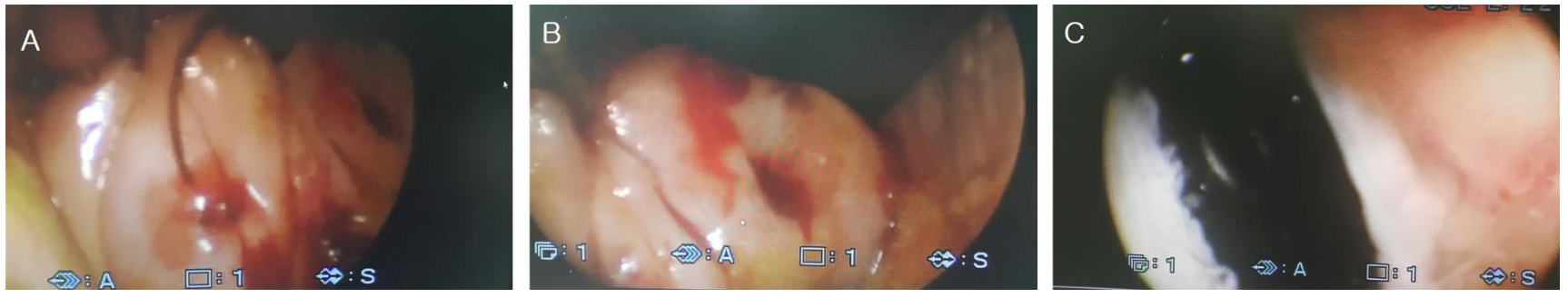

Fig. 5. A, B: Two cervix. C: dye-filled balloon is visible after septotomy.

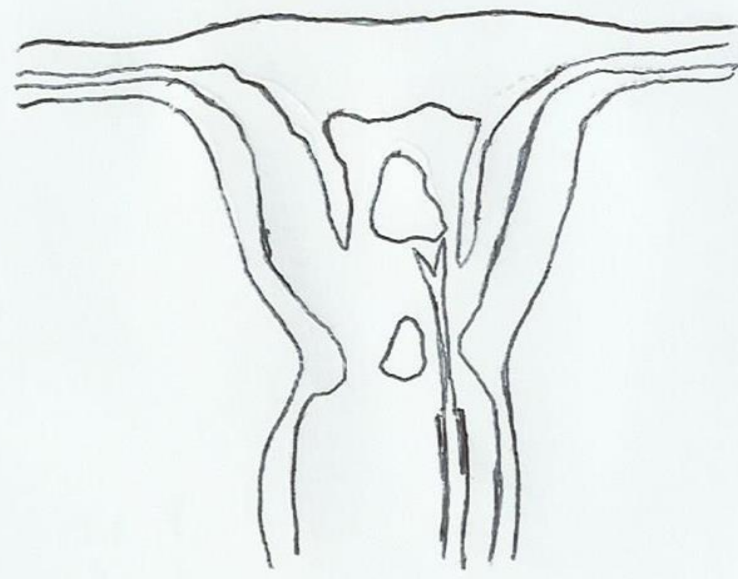

Fig. 6. Hysteroscopic septectomy.

fundal area and two cervical canals (Fig. 8).

The patient had IVF-ET and FET procedures following the surgery. She had a successful pregnancy and now is at 22 weeks of gestation (Fig. 9).

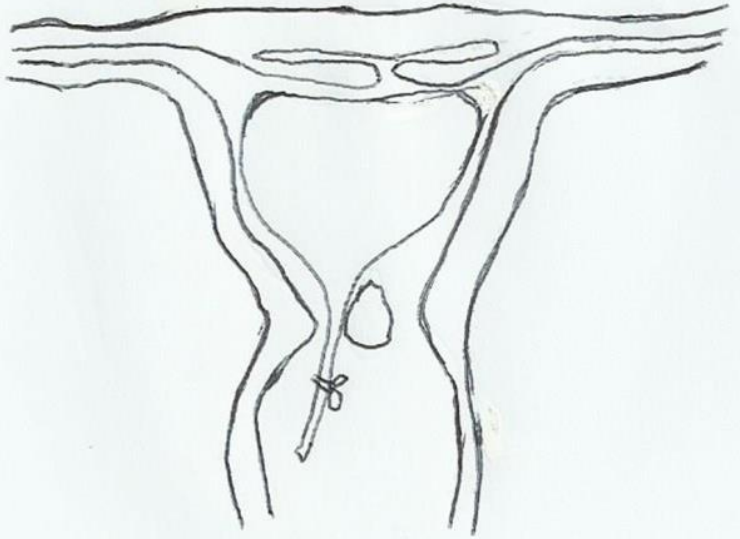

Fig. 7. Intra-uterine ballooning to compress septal endometrium on septectomy area.

\section{DISCUSSION}

Septate uterus is the most common uterine malformation of uterus. It is due to abnormal resorption of Müllerian 


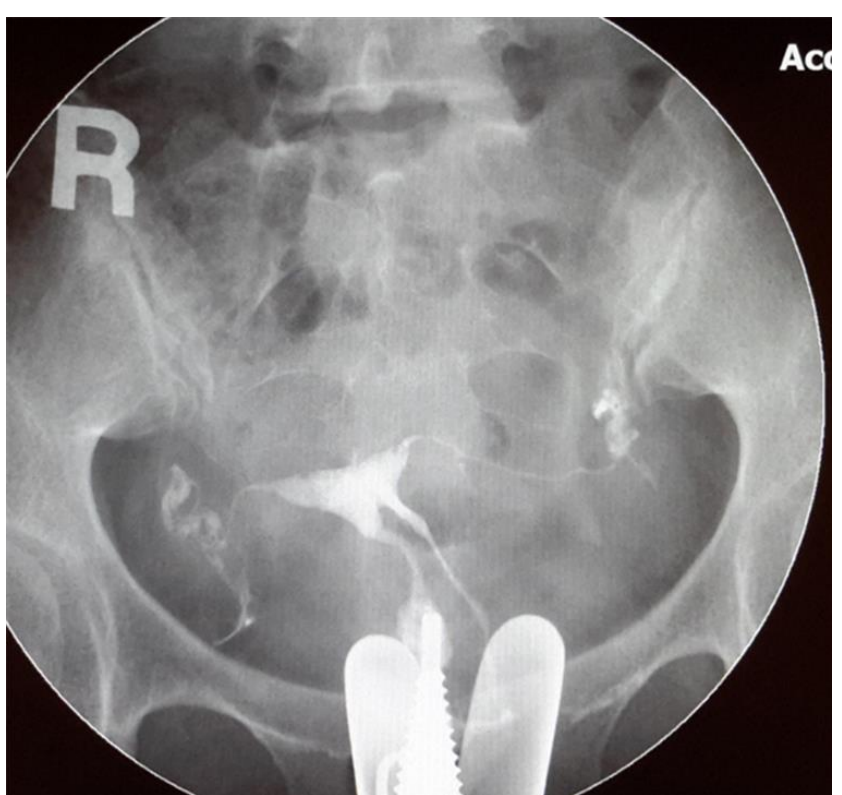

Fig. 8. Posop HSG of complete type of septum. HSG, hysterosalpingogram.

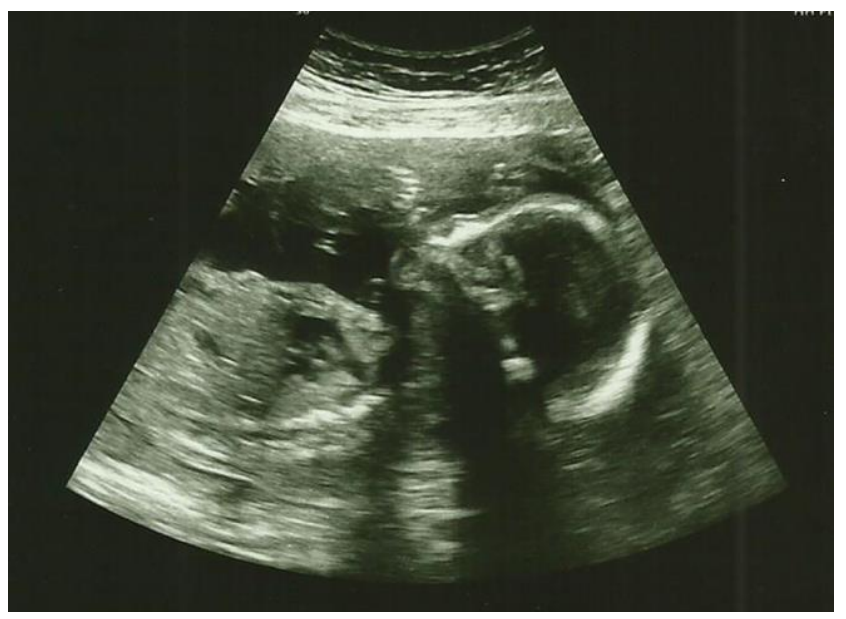

Fig. 9. Transabdominal sonography, IUP at 22 weeks. IUP, intrauterine pregnancy.

canal during embryogenesis (Chan et al., 2011). It is difficult to operate septoplasty in complete type of septate uterus which has thick septal wall and two fixed independent hemiuterus.

When hysteroscopy is inserted into the hemiuterus, it is difficult to evaluate exact septal wall area due to retroversion or anteversion and/or right or left deviation of uterus. Before surgery, MRI is useful to measure length and width of septal wall but it is not good enough to show the initial cutting point of septum. Concomitant laparoscopy during hysteroscopy is also useful to prevent perforation but it cannot visualize the initial point of cutting of septum (Tajiri et al., 2015).

Transabdominal and/or transvaginal ultrasonography may be better in finding the presence of septum is but it is not accurate (Niknejadi et al., 2014). Ballooning in one hemiuterus is helpful in evaluation of septate septal wall. Ballooning makes septum bulge so we can easily evaluate where the septal area is by hysteroscopy. Then we can confirm the septal area by pulling the tail of ballooning. We performed hysteroscopic septoplasty at ambulatory operating room without laparoscopy and without admission.

Laparoscopy may require more manpower, spaces, facilities and surgical instruments. Ambulatory hysteroscopic septoplasty using dye-filled ballooning can be easily done at ambulatory operating room and is a recommendable choice of treatment.

\section{REFERENCES}

Chan YY, Jayaprakasan K, Zamora J, Thornton JG, RaineFenning N, Coomarasamy A (2011) The prevalence of congenital uterine anomalies in unselected and highrisk populations: A systematic review. Hum Reprod Update 17:761-771.

Chen SQ, Deng N, Jiang HY, Li JB, Lu S, Yao SZ (2013) Management and reproductive outcome of complete septate uterus with duplicated cervix and vaginal septum: Review of 21 cases. Arch Gynecol Obstet 287: 709-714.

Esmaeilzadeh S, Delavar AM, Andarieh MG (2014) Reproductive outcome following hysteroscopic treatment of uterine septum. Mater Sociomed 26:366-371.

Fedele L, Bianchi S (1995) Hysteroscopic metroplasty for septate uterus. Obstet Gynecol Clin North Am 22:473489.

Grimbizis GF, Camus M, Tarlatzis BC, Bontis JN, Den- 
vroey P (2001) Clinical implication of uterine malformations and hysteroscopic treatment results. Hum Reprod Update 7:161-174.

Niknejadi M, Akhbari F, Niknejad F, Khalili G, Shiva M (2014) Comparison of two dimensional and live three dimensional ultrasounds for the diagnosis of septated uterus. Iran J Reprod Med 12:547-554.

Tajiri R, Ueda T, Aoyama Y, Sakuragi T, Tohoyama A, Okabe K, Nakagawa H, Kinjo Y, Hachisuga T (2015) Preg- nancy after hysteroscopic metroplasty under laparoscopy in a woman with complete septate uterus: A case report. J UOEH 37:17-22.

The American Fertility Society (1988) The American Fertility Society classifications of adnexal adhesions, distal tubal occlusion secondary to tubal ligation, tubal pregnancies, müllerian anomalies and intrauterine adhesions. Fertil Steril 49:944-955. 